

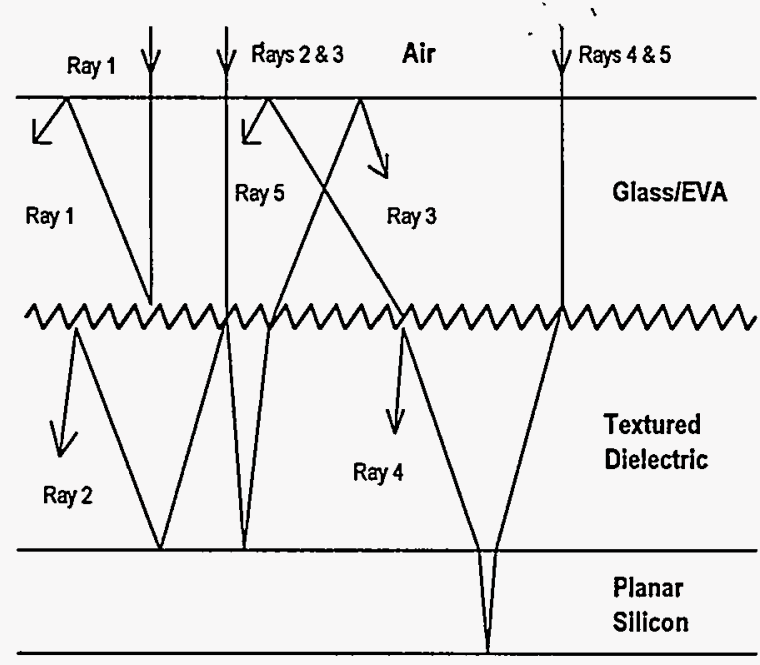

Not to Scale

Back Surface

Figure 1. Illustration of the optical structure of an encapsulated photovoltaic module with a planar solar cell and textured-dielectric coating.

total internal reflection either at the dielectric-glass interface $(60$ to $70 \%$, Ray 2) or, if transmitted at the dielectric-glass interface, at the glass-air interface (53\%, Ray 3). Finally, light not absorbed in the silicon (i.e., "escape reflectance") is transmitted back into the textured dielectric; these rays behave similarly to the rays reflected at the dielectric-silicon interface, so that many of these rays experience total internal reflection either at the dielectric-glass interface $(60$ to $70 \%$, Ray 4) or, if transmitted into the glass, at the glass-air interface $(53 \%$, Ray 5). The net result of the mechanisms illustrated with Rays 1, 2, and 3 is a reduction in "external" reflectance of the encapsulated silicon solar cell. The net result of the mechanisms illustrated with Rays 4 and 5 is to enhance the optical absorption of the silicon by providing multiple chances for absorption, which is similar to the "light trapping" effect in textured silicon cells [6].

\section{OPTICAL MODELLING}

We developed an optical model of a crystalline-silicon module and applied the model to three types of crystalline-silicon modules: (1) a textured silicon cell with a SLAR coating; (2) a planar silicon cell with a textured-dielectric coating (TDC); and (3) a planar silicon cell with a SLAR coating. Details of the optical model are described in the Appendix, and results of the calculations are presented in Table 1.

The textured-dielectric coating is very effective in both reducing reflectance losses and increasing optical absorption through optical confinement in the module. The active-area solar-weighted reflectance is reduced by over a factor of two for the planar-silicon cell with TDC compared to the planar-silicon cell with SLAR coating, which is the present standard commercial product. In addition, the short-circuit current densities of the textured-dielectric and textured-silicon modules are very similar.

The most important parameters for optimization of textured-dielectric coatings are (1) reflectance at the glass-textured dielectric interface and (2) the refractive index of the textured dielectric (Figure 2). Reflectance at the glass-textured dielectric interface is important because $53 \%$ of the light reflected at this interface escapes the module at the glass-air interface. A larger refractive index for the
Table 1: Calculated active-area short-circuit current density ( $J_{s c}$ in $\mathrm{mA} / \mathrm{cm}^{2}$ ) and solar-weighted reflectance ( $\langle\mathrm{R}\rangle$ in \%) of $\mathrm{c}-\mathrm{Si}$ photovoltaic modules with three different structures. Active-area means that grid reflectance was not included in the calculations, although the calculations included the reflectance at the air-glass interface. Calculation of $J_{s c}$ assumed unity internal quantum efficiency. These calculations used optimistic parameters for the textured-dielectric coating (TOC), including a refractive index of 2.6 and double-bounce reflectance at the glass-TDC interface.

\begin{tabular}{|c|c|c|c|}
\hline & $\begin{array}{c}\text { Textured Si } \\
\text { with SLAR }\end{array}$ & $\begin{array}{c}\text { Planar Si with } \\
\text { TDC }\end{array}$ & $\begin{array}{c}\text { Planar Si with } \\
\text { SLAR }\end{array}$ \\
\hline $\mathrm{J}_{\mathrm{se}}$ & 40.4 & 39.6 & 37.0 \\
\hline$\langle\mathrm{R}\rangle$ & 5.0 & 6.3 & 14.3 \\
\hline
\end{tabular}

textured-dielectric coating improves optical confinement in the textured dielectric, but can also increase reflectance at the glass-textured dielectric interface. Our application requires a refractive index greater than 2 for the textured-dielectric coating (Figure 2).

\section{EXPERIMENTAL RESULTS}

We experimentally confirmed the physics of our concept and of our optical models using thin-film diamond (TFD) coatings. These films were deposited onto silicon substrates by chemical vapor deposition (CVD). While CVD diamond is probably too expensive for solar cells, the TFD films are ideal for testing our optical model because these films are highly faceted (Figure 3 ) and have a large refractive index (around 2.4). We measured the hemispherical reflectance of asdeposited and of encapsulated TFD-coated silicon samples, and fitted the data with our optical model (Figure 4). The only adjustable parameter in the model is the fraction of single- and double-bounce reflectance at the glass-TFD interface, which is not a priori known without a detailed description of the geometrical distribution of the diamond crystals. The agreement between the data and our model is excellent, with the fraction of reflectance at the glass-TFD interface due to double bounce around $30 \%$.

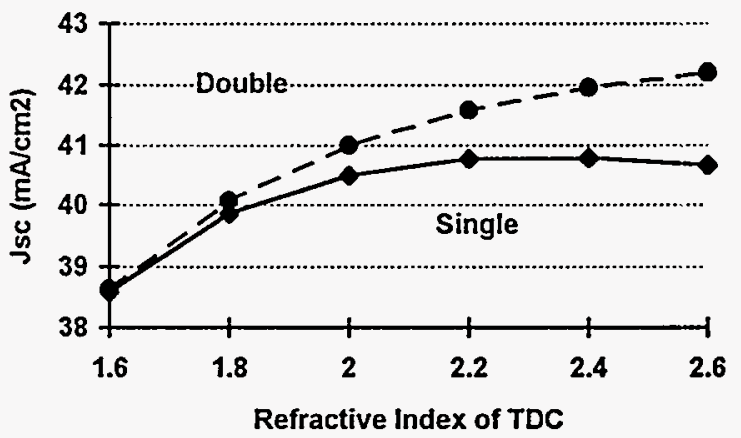

Figure 2. The effect of varying the refractive index of the textureddielectric coating (TDC) and of the reflectance at the glass-TDC interface. "Single" and "double" refer to the number of bounces a ray experiences before reflecting from the glass-TDC interface. Hence, reflectance at the glass-TDC interface is much lower for double-bounce than for single-bounce reflectance. 


\section{DISCLAIMER}

Portions of this document may be illegible in electronic image products. Images are produced from the best available original document. 


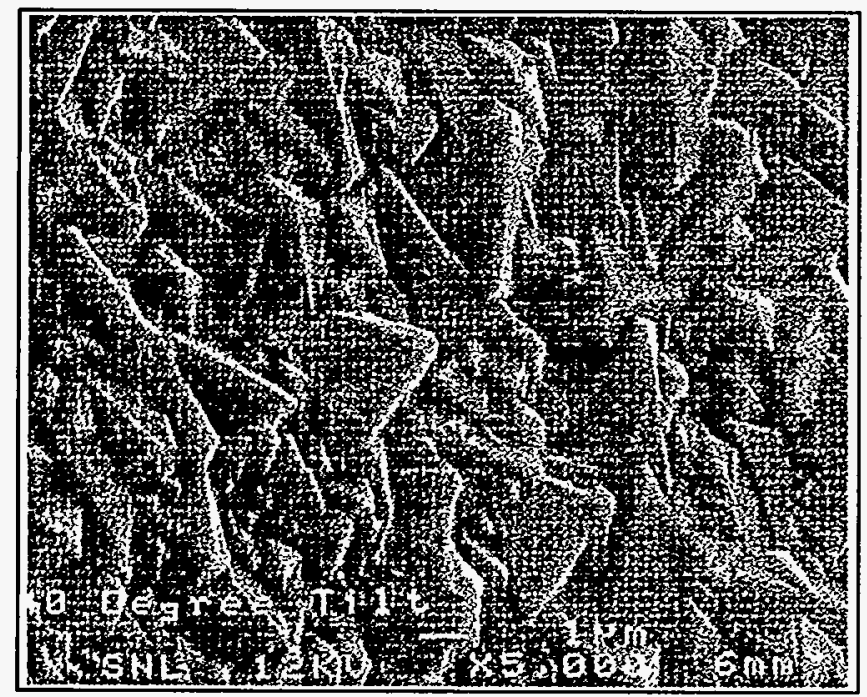

Figure 3. SEM photomicrograph of surface of thin-film diamond that was deposited by chemical vapor deposition on a silicon wafer.

The solar-weighted reflectance of the encapsulated TFD-silicon sample is only around $7.3 \%$. This value is around one-half the activearea solar-weighted reflectance of a typical mc-Si module (planar cell with SLAR - see Table 1) despite the fact that the TFD film was not optimized for our application. The module reflectance could be further reduced with either an antireflection coating over the TFD film or optimization of the TFD deposition so that more rays experience double-bounce reflectance at the glass-TFD interface.

We also evaluated textured-Zno films on silicon wafers. These films were deposited by atmospheric-pressure chemical vapor deposition in a belt furnace. These films had a slightly higher reflectance after encapsulation compared to the encapsulated TFD-coated silicon samples, which is probably due to the lower refractive index of $\mathrm{ZnO}$ $(n=2.0)$.

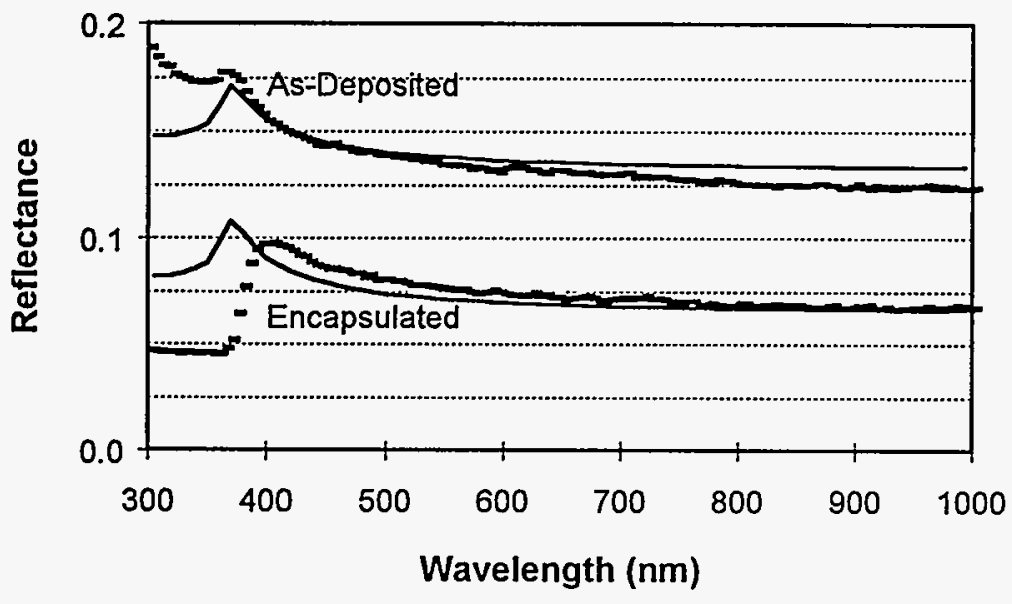

Figure 4. Hemispherical reflectance of silicon wafer coated with thin-film diamond before and after encapsulation. Model fit is solid line and data is dashed line.

\section{DISCUSSION AND SUMMARY}

Light-trapping geometries for increasing the optical absorptance of solar cells may be classified into two categories - internal confinement, where the optical confinement occurs internally in the solar cell due to scattering at the cell's surfaces, and external confinement, where the optical confinement occurs external to the cell in external cavities [7]. Use of the module encapsulation for reflectance control is therefore a type of external confinement [7]. External confinement has generally been examined for use as either an optical concentrator or for increasing the optical absorptance of the solar cell. This paper, however, demonstrates that external confinement is also useful for controlling reflectance. The use of the textured-dielectric coating should also allow the use of thinner mc-Si cells, although we did not examine this possibility in this paper.

Textured-dielectric coatings have several practical advantages compared to other approaches for controlling reflectance in mc-Si modules. Suitable materials for the textured-dielectric coating include $\mathrm{ZnO}, \mathrm{TiO}_{2}$, and $\mathrm{SnO}_{2}$; these materials have large refractive indices $(n>2)$ and have been deposited with textured surfaces and with lowcost technologies [5]. The textured-dielectric coating introduces no complications in the cell process if the coating is applied after the grid metallization. In contrast, mechanical texturing produce surfaces with large texture dimensions that can significantly complicate the cell fabrication process [9]. In addition, a TDC deposited over the grids should reduce grid obscuration losses by recovering reflected light from the grid through optical confinement in the module encapsulation.

In conclusion, we presented a new method for reducing the reflectance and improving the optical absorptance of photovoltaic modules using textured-dielectric coatings. The new method is useful with planarsurface solar cells (e.g., mc-Si) and has potential cost and performance advantages over other reflectance-control approaches for mc-Si solar cells.

\section{APPENDIX: OPTICAL MODEL OF A C-SI PHOTOVOLTAIC} MODULE

A c-Si photovoltaic module typically has the silicon solar cell encapsulated under glass with a polymeric material. The glass and polymeric material (generally ethylene vinyl acetate - EVA) have very similar refractive indices, so that the optical interface between the EVA and glass may be ignored in optical models. An illustration of the model is presented in Figure A1. The model consists of four optically thick layers. The first layer (Layer 0 ) is the incident optical medium; i.e., Layer 0 is air with a refractive index of 1 . Layer 1 is the encapsulant (glass/EVA) and has a refractive index of 1.50. Layer 2 is the textured-dielectric film with a high refractive index. Layer 3 is the silicon cell and is characterized with both a refractive index and an absorption coefficient.

We define an effective intensity for forward and backward traversing waves in each layer $\left(\mathrm{l}_{i}^{+}\right.$and $\left.\mathrm{l}_{j}\right)$. Each interface is characterized by a reflectance and transmittance coefficient. Layer 3 is further characterized by an effective per-pass bulk tansmittance $\left(T_{b}\right)$ and a back-surface reflectance $\left(R_{b}\right)$. $T_{b}$ is a function of the absorption coefficient and the cell 


\begin{tabular}{llll} 
R01,T01 & $\downarrow I_{0}^{+}$ & $I_{0}^{-} \uparrow$ & Layer 0 (air) \\
\hline R10,T10 & $\downarrow I_{1}^{+}$ & $I_{1}^{-} \uparrow$ & Layer 1 (glass) \\
\hline R12,T12 & $\downarrow I_{2}^{+}$ & $I_{2}^{-} \uparrow$ & Lajer 2 (TDC)) \\
R23,T21 & \\
\hline R32,T32 & $\downarrow I_{3}^{+}$ & $I_{3}^{-} \uparrow$ & Layer 3 (solar cel) \\
Rb and To &
\end{tabular}

Figure A2. Illustration of the thick-film optical model of a photovoltaic module. TDC is textured-dielectric coating.

width. The resulting set of algebraic equations are solved by elimination. Krauter et alia recently described a similar optical model of one-sun photovoltaic modules that includes non-normal incidence and polarization effects [9].

The optical model is relatively straightforward while the physics of the model is embedded in the interfacial reflection and transmission coefficients $\left(R_{i j}\right.$ and $\left.T_{i j}\right)$. We assume no absorption at an interface, so $T_{\bar{i}}$ is equal to 1 minus $R_{\bar{j}}$. For a planar interface, refiectance at the $i-j$ interface $R_{i j}$ is equal to the reflectance at the $j-i$ interface $R_{j i}$ due to symmetry of the Fresnel equations, which leads to minimal optical confinement in Layer $\mathrm{j}$. For a textured interface, we assume that both the reflected and the transmitted rays are completely randomized. For example, assume that medium $\mathrm{j}$ has a higher refractive index than medium $i$. For a textured interface, the reflectance at the $\mathrm{j}-\mathrm{j}$ interface (rays incident from the Layer i) can be very small, particularly if we assume that the rays undergo "double bounce" or if the interface includes a thin-film antireflection coating. On the other hand, the reflectance at the $j-i$ interface can now be quite high due to the assumption of randomized rays inside medium $j$ and to total internal reflection at the $j-i$ interface. In the limit of complete randomization of the direction of rays, the percentage of rays reflected by total internal reflection at the $j-i$ interface is given by the following expression [6]:

$$
R_{j i}=1-T_{j} /\left(n_{j j}\right)^{2} \text { and } n_{j i}=n_{j} / n_{i}
$$

The bulk transmittance $T_{b}$ in the silicon depends upon the assumed distribution of rays. For a planar silicon cell with incident parallel rays, the rays have uniform directions and traverse the silicon perpendicular to the surfaces. The absorption of these rays is simply expressed with an exponential function $(\exp (-\alpha w))$. For the textured silicon cell, the rays are assumed to be randomized similar to conventional lighttrapping calculations [6]. For the case of a textured dielectric with a planar dielectric-silicon interface, the rays transmitted into the silicon subtend an angle of double the critical angle at the silicon-dielectric interface. This angle is about $94^{\circ}$ for a refractive index of 2.6 for the dielectric film and a refractive index of 3.55 for silicon. For either the textured silicon or the textured dielectric cases, the transmittance is an integral over the distribution of rays [10].

\section{ACKNOWLEDGMENTS}

The thin-film diamond sample was provided by $W$. Hsu. The reflectance measurements were performed by $L$. W. Irwin. We would also like to acknowledge useful discussions that contributed to this work with S. Narayanan, B. L. Sopori, F. Wald, and P. A. Basore.

\section{REFERENCES}

PVSC refers to Proc. of the IEEE Photovoltaic Specialists Conference.

1. B. L. Sopori, Solar Cells, 28, pp.253-260 (1990).

2. S. Narayanan, et alia, 21st PVSC, pp. 678-680 (1990).

3. H. Nakaya, et alia, Techn. Digest of the 7 th Intern. Photovoltaic Science and Engineering Conf., pp. $91-92$ (1993).

4. Y. S. Tsuo, et alia, 23rd PVSC, pp. 287-293 (1992).

5. H. Takato, et alia, Japn. J. Appl. Phys., 31, pp. L1665-L1667 (1992).

6. E. Yablanovitch and G. C. Cody, IEEE Trans. Elect. Dev., ED-29, pp. 300-305 (1982).

7. J. C. Minano, "Optical confinement in photovoltaics," in Physical Limitations to Photovoltaic Energy Conversions, A. Luque and G. L. Araujo, eds., Adam Hilger, Bristol, 1990.

8. J. M. Gee, et alia, "The effect of encapsulation on the reflectance of photovoltaic modules using textured, multicrystalline-silicon solar cells," this conference.

9. S. Krauter, et alia, $12^{\text {th }}$ Eur. Photovoltaic Solar Energy Conf., pp. 1198-1201 (1994).

10. J. M. Gee, $20^{\text {th }}$ PVSC, pp. $549-554$ (1988).

\section{DISCLAIMER}

This report was prepared as an account of work sponsored by an agency of the United States Government. Neither the United States Government nor any agency thereof, nor any of their employees, makes any warranty, express or implied, or assumes any legal liability or responsibility for the accuracy, completeness, or usefulness of any information, apparatus, product, or process disclosed, or represents that its use would not infringe privately owned rights. Reference herein to any specific commercial product, process, or service by trade name, trademark, manufacturer, or otherwise does not necessarily constitute or imply its endorsement, recommendation, or favoring by the United States Government or any agency thereof. The views and opinions of authors expressed herein do not necessarily state or reflect those of the United States Government or any agency thereof. 